\title{
Total pancreatectomy for chronic pancreatitis
}

\author{
I P LINEHAN, M A LAMBERT, D C BROWN, A B KURTZ, P B COTTON, AND
} R C G RUSSELL

From the Departments of Surgery, Gastroenterology and Medicine, The Middlesex Hospital and Medical School, London

SUMMARY The operation of total pancreatectomy is performed rarely. Its role in the management of patients with chronic pancreatitis remains to be elucidated. We have reviewed our series of 29 total pancreatectomies for benign disease [14 women median age 39 years; 15 men median age 34 years]. Twelve underwent standard total pancreatectomy, in 17 duodenum preserving total pancreatectomy (DPTP) was performed. There was one death (mortality $3.4 \%$ ). In no patient was the total pancreatectomy the first operative procedure. The patients were compared with age and sex matched diabetic control subjects selected on a best fit basis from the diabetic clinic database. The aetiology of the pancreatitis was idiopathic nine, pancreas divisum nine, alcohol eight and other causes three. The indication for surgery was pain 27, acute pancreatitis one and cholangitis with pancreatitis one. The complications of the procedures were mainly caused by infection [wound three, chest six and central line sepsis four] and in two there was a leak from the duodenum; no patient required re-operation. The postoperative stay [standard total, median 21 days (range 13-98) DPTP median 31 days (range 17-49)] has lengthened over the period due to greater attention to analgesic, diabetic and enzyme deficiency control before discharge. In standard total pancreatectomy there were five major hypoglycaemic episodes with only two in 17 DPTP patients. The per cent ideal body weight, the insulin requirement and the $\mathrm{HbAl}$ compared less well in standard total pancreatectomy group compared with controls than did DPTP. With both groups large doses of enzyme replacement were required, and this proved of importance in diabetic control. Our experience with total pancreatectomy suggests that pain will be improved in over $80 \%$ of patients and that the results of surgery will improve with prolonged follow up provided attention is given to analgesic abuse, enzyme deficiency and diabetes.

The role of surgery in the management of chronic pancreatitis is a subject of debate. ${ }^{\text {M }}$ Most would agree that the place for surgery is clear when there is a complication of chronic pancreatitis amenable to surgical intervention. Unfortunately the problem often facing the clinician is that of a patient with chronic pain, on an increasing dosage and strength of analgesia, whose quality of life is destroyed by the effects of both pain and analgesia. There is a group of patients who fail to respond to, or who relapse after, non-surgical procedures such as nerve blocks and endoscopic sphincterotomies: of these, there are some whose symptoms are not relieved by pancreatic Address for correspondence: Mr R C G Russell, FRCS, Consultant Surgeon, The Middlesex Hospital, London W1N 8AA.

Received for publication 31 August 1987. drainage procedures or partial pancreatectomies. In the patient with intractable pancreatic pain the lesser operative procedures have usually been tried but have failed. This type of patient is usually on high doses of narcotic analgesics but still incapacitated by unremitting pain; there is little to offer than total pancreatectomy.

In the management of a benign disease it is appropriate, when considering major ablative resection, to try to minimise the sequelae that may follow non-essential parts of the standard procedure. Partial gastrectomy has been done with total pancreatectomy since the earliest days ${ }^{23}$; however, there is increasing evidence that total pancreatectomy is possible and safe if the stomach, pylorus ${ }^{47}$ and (where possible) the duodenum ${ }^{8-10}$ are preserved. If 
the patient has not undergone a previous Whippletype pancreatoduodenectomy the procedure of choice performed in this department is the duodenum preserving total pancreatectomy. ${ }^{8,}$

A major criticism of total pancreatectomy is that the resultant diabetes is labile, difficult to manage and dangerous." This paper reviews our experience with total pancreatectomy and examines the management of these patients in the long term.

\section{Methods}

\section{PATIENTS}

Since 1979 , any patient who had undergone one of two types of total pancreatectomy carried out in this hospital (Fig. 1) was under the joint care of a consultant physician (PBC) and a consultant surgeon (RCGR). During this time a specific follow up clinic was established in conjunction with a consultant physician responsible for diabetic care (ABK). Apart from regular review the patients had open access to this clinic if they had problems.

Two main types of operation were done; the standard total pancreatectomy and the duodenum preserving total pancreatectomy. In the former a standard Whipple type procedure was carried out removing the antrum, pylorus, duodenum and all the remaining pancreas. In the latter the stomach, pylorus and duodenum were preserved but all the pancreas was removed."

In these 29 patients 26 previous pancreatic resections had been performed.

Twenty seven of the 29 patients described attend regularly and have been seen in the two months before the preparation date of this manuscript (October, 1986).

Two patients are not included in the follow up data: one patient died two days after surgery; one patient has been lost to follow up, but a report in November 1985 stated that he was alive four years after total pancreatectomy.

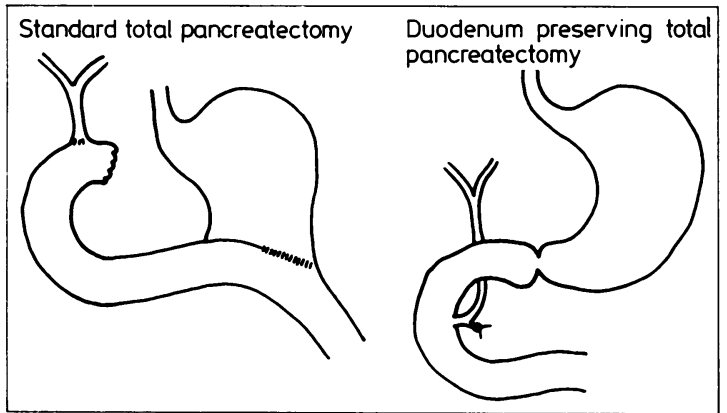

Figure Diagrammatic representation of the two types of pancreatic operation carried out.
Three patients, whose management has been hampered by major psychological problems have been excluded: one patient has proven hypoglycaemia artefacta; one patient refuses to eat; one patient eats but is thought to induce vomiting.

These patients represent failure of patient selection rather than of operative technique. They are excluded from analysis in this series as their insulin requirement, body weight and enzyme replacement are not representative of a 'normal' postoperative subject.

The assessment of the diabetic control was based on the clinical and biochemical review on each clinic visit. Three parameters were derived for the purpose of group comparisons: (a) percentage ideal body weight (\%IBW) - the ideal body weight was taken from each patient's height and sex, assuming a medium frame size ${ }^{12}$; the weight recorded at the most recent clinic visit was expressed as a percentage of this ideal body weight. This was considered to be a crude index of nutritional status. (b) Insulin requirement $/ \mathrm{kg} / 24$ hours (IR) - the daily dose of insulin recorded at the most recent visit, was expressed in units per $\mathrm{kg}$ body weight. (c) The mean glycaemic control $(\mathrm{HbAl})$ - all the values of the HbAlc were noted, where possible for the preceding 12 months.

Each total pancreatectomy patient was matched for age and sex with a non-surgical insulin dependent patient from the diabetic clinic. The three parameters were calculated for the controls; these were compared using a Mann-Whitney test in the groups: (1) all pancreatectomies versus controls; (2) standard pancreatectomies versus controls; (3) duodenum preserving pancreatectomies versus controls.

The incidence of severe and moderate hypoglycaemic episodes was noted for patients and controls: a severe episode being one in which the patient is admitted to hospital unconscious, a moderate episode being one in which someone else has to intervene in order to abort the attack but the patient does not require admission.

\section{Results}

Between 1979 and the 31 May 1986, 259 operative pancreatic procedures were carried out for benign disease at the Middlesex Hospital. Twenty eight total pancreatectomies were done for chronic pancreatitis and one for acute pancreatitis. Total pancreatectomy therefore comprised only $11.2 \%$ of all pancreatic procedures for benign disease.

There was one death (mortality $=3.4 \%$ ): this was in the case where surgery was performed for fulminant acute pancreatitis. A 23 year old woman, who as a child had had surgical correction of Fallot's tetralogy, developed acute pancreatitis in the remnant 
Table 1 Age at operation and follow up experience

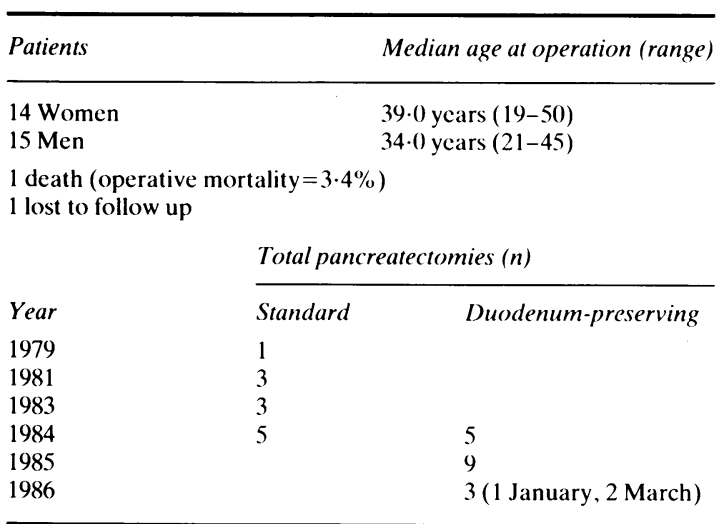

Median follow up $=22 \cdot 0$ months $(6-89)$; cumulative experience $=$ $60 \cdot 8$ patient years.

Table 2 Age and duration of disease by aetiological groups

\begin{tabular}{lllr}
\hline Aetiology & $n$ & $\begin{array}{l}\text { Age at operation } \\
\text { Median (range) }\end{array}$ & $\begin{array}{l}\text { Duration in years } \\
\text { Median (range) }\end{array}$ \\
\hline Idiopathic & 9 & $38(21-46)$ & $8(2-15)$ \\
P divisum & 9 & $40(23-50)$ & $11(3-35)$ \\
Alcohol & 8 & $36(23-45)$ & $3(2-13)$ \\
Congenital & 1 & 19 & 17 \\
Trauma & 1 & 33 & 14 \\
Iatrogenic & 1 & 38 & 7 \\
\hline
\end{tabular}

after a pancreatoduodenectomy for chronic pancreatitis. Supportive treatment failed and she underwent an emergency completion pancreatectomy. She died two days postoperatively of adult respiratory distress syndrome.

Table 1 summarises the age at operation of the 29 patients and follow up experience of 27 . One patient lost to follow up is known to be alive. No patient has been followed up less than six months.

\section{AETIOLOGY}

Postulated aetiologies are listed in Table 2 with the median age at operation and median duration of disease before total pancreatectomy.

The congenital case presented with jaundice at the age of 2 years and was found to have a choledochal cyst which was drained. At the age of 8 she developed pancreatitis and by the age of 19 had undergone another three major pancreatobiliary surgical procedures by which time she had end stage chronic pancreatitis requiring $2400 \mathrm{mg}$ pethidine/day. The traumatic case arose from blunt abdominal injury during a football match in which the pancreas was transected by compression against the spine; he was also noted to have pancreas divisum. The iatrogenic case had a biliary operation carried out abroad for a benign tumour of the gall bladder, this was followed by the onset of her pancreatitis and therefore we must consider the operation to have been the likely cause. We do not know the exact nature of the biliary surgery in this case.

\section{PREVIOUS PROCEDURES}

Tables 3 and 4 list the numbers of non-operative and operative procedures, respectively, carried out on these patients before the total pancreatectomy. In Table 3, nerve block includes one epidural for short term relief and seven coeliac plexus blocks. The three endoscopic accessory sphincteroplasties were done before we abandoned this procedure because of its lack of benefit and high technical failure rate. In Table 4 the bypasses include biliary and gastrointestinal bypasses. Six of the 11 drainage procedures undertaken in the pancreas divisum group were operative accessory sphincteroplasties. In none of the patients was total pancreatectomy the first operative procedure.

Not all of these 66 previous operative procedures had been performed in this department.

PREOPERATIVE DIABETIC STATUS

At the time of total pancreatectomy 19 patients were

Table 3 Non operative procedures before total pancreatectomy

\begin{tabular}{|c|c|c|c|c|c|}
\hline \multirow[b]{2}{*}{ Aetiology } & \multirow[b]{2}{*}{$n$} & \multirow{2}{*}{$\begin{array}{l}\text { Nerve } \\
\text { blocks }\end{array}$} & \multicolumn{2}{|c|}{ Sphincterotomies } & Endoscopic \\
\hline & & & Accessory & Major & Duct ablation \\
\hline Idiopathic & 9 & 5 & & 1 & 1 \\
\hline P divisum & 9 & & 3 & & \\
\hline Alcohol & 8 & 3 & & & \\
\hline Congenital & 1 & & & & \\
\hline Trauma & 1 & & & & \\
\hline Iatrogenic & 1 & & & & \\
\hline
\end{tabular}

Total number of non-operative procedures $=14$.

Table 4 Operative procedures before total pancreatectomy

\begin{tabular}{|c|c|c|c|c|c|c|}
\hline \multirow[b]{2}{*}{ Aetiology } & \multirow[b]{2}{*}{$n$} & \multirow{2}{*}{$\begin{array}{l}\text { Laparo- } \\
\text { tomy }\end{array}$} & \multirow{2}{*}{ Chole } & \multirow[b]{2}{*}{ Bypass } & \multicolumn{2}{|l|}{ Pancreatic } \\
\hline & & & & & Resection & Drainage \\
\hline Idiopathic & 9 & 1 & 4 & 1 & 8 & 2 \\
\hline$P$ divisum & 9 & & 1 & 1 & 6 & 11 \\
\hline Alcohol & 8 & 4 & 4 & 1 & 7 & 1 \\
\hline Congenital & 1 & & & 2 & 2 & 2 \\
\hline Trauma & 1 & & 1 & 1 & 2 & 1 \\
\hline Iatrogenic & 1 & & 1 & 1 & 1 & \\
\hline All patients & 29 & 5 & 11 & 7 & 26 & 17 \\
\hline
\end{tabular}

Total number of operative procedures $=66$. 
not diabetic; seven were insulin dependent, two on oral hypoglycaemics and one on diet control alone.

\section{IN DICATION FOR SURGERY}

No patient underwent total pancreatectomy until prolonged and repeated periods of inpatient and outpatient therapy had failed. The diagnosis of all patients was reviewed by a physician before referral for total pancreatectomy and frequently independent opinions were sort. All patients were counselled about the diabetes and patients in the latter half of the series spoke to patients who had had such an operation. The authors were aware, as a result of ultrasound imaging, that the pancreas was not grossly abnormal in some patients; in these subjects the greatest care was taken to exclude alternative pathology, and only to undertake surgery as the last resort.

Twenty seven of the total pancreatectomies were carried out for relief of pain. The one case done for fulminant pancreatitis has already been described. One patient who had previously undergone a distal pancreatectomy for chronic pancreatitis, developed further pancreatitis in the head causing biliary obstruction and cholangitis; he had a completion pancreatectomy undertaken as he was already insulin dependent and required enzyme replacements.

\section{PROCEDURES CARRIED OUT}

The 29 cases comprised 12 standard pancreatectomies (pancreatoduodenectomy and antrectomy) and 17 duodenum preserving total pancreatectomies. (Fig. 1)

\section{EARLY COMPLICATIONS}

Ten of the 28 surviving patients had no early complications after surgery. One patient had a pneumothorax secondary to an attempt at subclavian vein cannulation for parenteral nutrition. One patient developed a psychosis, presumably from alcohol withdrawal. One patient had a wound haematoma which discharged spontaneously. One patient was found to be anaemic and was transfused five days postoperatively; this was thought to be because of inadequate peroperative replacement.

The major problem was with sepsis. One patient had a urinary tract infection, two had wound infections and six had chest infections. Four patients had central (feeding) line sepsis which in three caused septicaemia.

Four patients had complications specific to duodenum preserving pancreatectomy. One patient was noted to be draining bile postoperatively presumably as a result of unrecognised bile duct damage, this settled spontaneously; he became the first patient with a late biliary stricture. One patient had a bout of haematemesis and melaena for which on endoscopy no cause could be found; this settled on conservative management and was thought to be caused by bleeding from the duodenum. The last two patients in this series to undergo pancreatectomy (in February and March 1986) developed leaks from the pancreatic duct stump, one was accompanied by significant intra-abdominal bleeding and required ultrasound guided drainage; the other stump leak drained through the drains left at operation, requiring no intervention. Both the leaks stopped spontaneously within 21 days and the tracks have remained healed since. Four subsequent patients not included in this series because of short follow up have had no duodenal complication.

Four patients initially had difficulty with stabilisation of diabetes in the immediate postoperative period: of these, one has since been lost to follow up, one is now known to have hypoglycaemia artifacta although this was not the case in the immediate postoperative period and two now have no problems with diabetic control despite full time employment involving shiftwork.

Two patients developed a recurrence of their usual pain before discharge; this settled spontaneously.

POSTOPERATIVE STAY IN HOSPITAL

The median postoperative stay for the standard total pancreatectomies was 21 days (range $=13-98$ ) and for duodenum preserving total pancreatectomies was 31 days (range $=17-49$ ). The longer hospital stay is more related to the recent extra care with diabetic education, and attempt to wean off all analgesics before leaving hospital.

Table 5 Readmissions

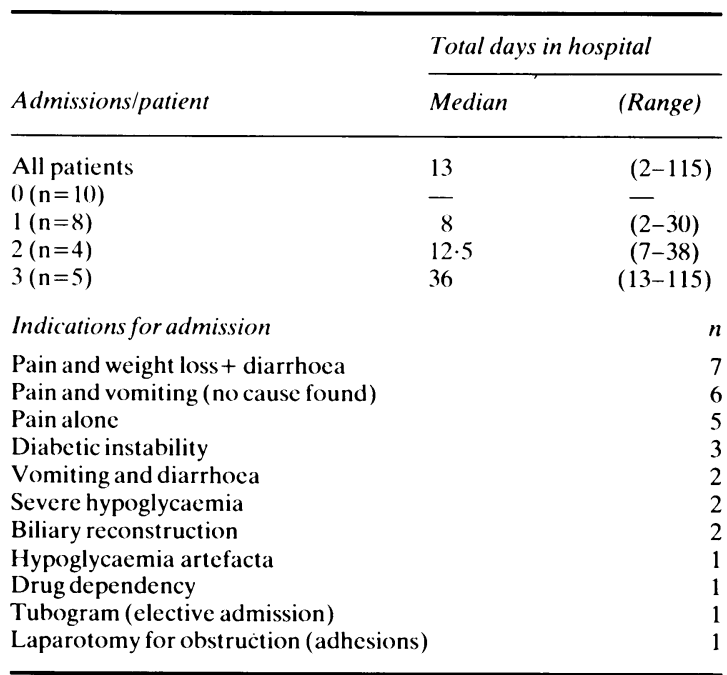


HISTOLOGY

In two cases the pancreas showed acute pancreatitis, one with abscess formation; these were the only two cases in which the indication for total pancreatectomy was other than pain. In 25 cases the removed pancreas showed chronic pancreatitis, but in three it was only mild. In one case the pancreas showed small adenomatous nodules whose significance was indeterminate but no other abnormality. In one case the pancreas was within normal limits, but no other abnormality has been found on subsequent follow up, and at one year the progress of the patient was good without pain.

SUBSEQUENT READMISSIONS

Seventeen patients have required readmission, the total number of readmissions for the group was 31 . One of these admissions was planned for a postoperative tubogram, the remaining 30 were for the management of problems. The indications and numbers of admissions are given in Table 5 with median and cumulative duration of stay.

\section{LATE NON-DIABETIC COMPLICATIONS}

Of the 27 patients followed up there were only two patients with a late complication directly attributable to the procedure other than hypoglycaemia: both had recurrent cholangitis after a duodenum preserving total pancreatectomy, secondary to a biliary stricture. This required biliary reconstruction six months after the pancreatectomy in one case, done 10 months ago; he remains well and free from cholangitis. The other case was managed by the endoscopic insertion of stents less than three months ago.

POSTOPERATIVE DIABETIC STATUS

The patients are all managed by 'normal' - that is, twice daily injection of a combination of rapidly absorbed and intermediate insulins, with the exception of two patients who are controlled using an insulin pump. One of these patients was in the 'anorexic' group and one was a young fit man. Patients routinely monitor their blood glucose with reagent strips and also tested their urine - thus assessing possible calorie loss.

One patient who has been insulin dependent since 1977 and had a total pancreatectomy done in 1983 has peripheral neuropathy; this was only represented by loss of the ankle jerks. One patient who had only been diabetic since total pancreatectomy in 1984 had possible peripheral neuropathy, the diagnosis complicated by carpal tunnel syndrome. Neither of these patients had any history of alcohol abuse.

There were no other longterm complications of diabetes but the follow up period was too short, even for our earliest case, to draw any conclusions. The
Table 6 Hypoglycaemic episodes in the pancreatectomy groups and controls

\begin{tabular}{llll}
\hline & & \multicolumn{2}{l}{ Hypoglycaemic episodes } \\
\cline { 3 - 4 } & & Moderate & Severe \\
\hline $\begin{array}{c}\text { Standard total } \\
\text { pancreatectomy } \\
\begin{array}{c}\text { Duodenal preserving } \\
\text { pancreatectomy } \\
\text { Diabetic controls }\end{array}\end{array}$ & $\begin{array}{l}(\mathrm{n}=10) \\
(\mathrm{n}=27)\end{array}$ & 0 & $5\left(3^{*}\right)$ \\
\hline
\end{tabular}

* During periods of severe malabsorption.

frequency of hypoglycaemic episodes is tabulated in Table 6 . The standard total pancreatectomy group appeared to have a high number of severe hypoglycaemic episodes compared with the controls, however, three of these episodes occurred very early on when the patients had marked diarrhoea as a result of pancreatic insufficiency. Although mild hypoglycaemic episodes are not routinely recorded by the patients our impression is that these are more frequent if episodes of diarrhoea and malabsorption occur.

Comparisons of the different groups and diabetic controls are summarised in Table 7 . There is a significant difference between the whole total pancreatectomy group and the diabetic controls, however, when the two different operative procedure groups are compared independently with their respective controls a significant difference is shown between the standard pancreatectomy group and the diabetic controls for all three parameters. There was no significant difference between the duodenum preserving pancreatectomy group and the controls for any of the three parameters compared.

PANCREATIC ENZYME REPLACEMENT THERAPY The status of the patients with respect to pancreatic enzyme replacement therapy is summarised in Table 8 . Of the 24 patients included in this part of the study, we do not have adequate records on two, 18 are on stable doses of enzyme replacement with no diarrhoea (up to four bowel actions per day), six are unstable and are currently altering their enzyme replacement therapy. Of the six who are unstable one patient is thought to have the dumping syndrome after a standard total pancreatectomy but has refused to have a dumping provocation test, and three seem to be resistant to all the currently available preparations despite high doses and $\mathrm{H}_{2}$ blockers.

Pancreatic insufficiency has a relationship with diabetic management. Of the eight patients who had had severe hypoglycaemic episodes four of these occurred at times when the patients had diarrhoea. 
Table 7 Comparisons of pancreatectomy groups and controls

\begin{tabular}{|c|c|c|c|c|}
\hline & $n$ & $\begin{array}{l}\% \text { IBW } \\
\text { Median (range) }\end{array}$ & $\begin{array}{l}\text { Insulin } \\
\text { Units/kg/24 hr } \\
\text { Median (range) }\end{array}$ & $\begin{array}{l}\text { HbAl } \\
\text { Median (range) }\end{array}$ \\
\hline All & 24 & $100 \cdot 7(74 \cdot 8-138 \cdot 2)$ & $0.55(0 \cdot 33-0 \cdot 81)$ & $10 \cdot 3(6 \cdot 7-14 \cdot 8)$ \\
\hline Controls & 24 & $111 \cdot 0(95 \cdot()-135 \cdot 2)$ & $(0.61(0.41-1.01)$ & $9 \cdot 8(6 \cdot 8-14 \cdot 2)$ \\
\hline $\mathrm{p}$ & & $(0 \cdot() 1$ & 0.28 & 0.68 \\
\hline Standard & 10 & $89 \cdot 7(74 \cdot 8-110 \cdot 4)$ & $0.49(0.32-0.71)$ & $11 \cdot 2(8 \cdot 6-14 \cdot 8)$ \\
\hline Controls & 10 & $115 \cdot 6(99 \cdot 3-125 \cdot 7)$ & (0.64 (0.46-0.88) & $10 \cdot 0(6 \cdot 7-14 \cdot 0)$ \\
\hline $\mathrm{p}$ & & 0.004 & 0.024 & 0.03 \\
\hline DPTP & 14 & $101.9(80 \cdot 9-138 \cdot 2)$ & $0.66(0.35-0.81)$ & $10 \cdot 0(6 \cdot 8-11 \cdot 7)$ \\
\hline Controls & 14 & $109 \cdot 7(95 \cdot()-135 \cdot 2)$ & $0.61(0.41-1.01)$ & $9 \cdot 2(6 \cdot 8-14 \cdot 2)$ \\
\hline $\mathrm{p}$ & & 0.44 & 0.67 & $(0.19$ \\
\hline
\end{tabular}

DPTP $=$ duodenum-preserving total pancreatectomy group.

Four patients who had diarrhoea and have since had the pancreatic enzyme replacement altered to control this, have volunteered the fact that their diabetes had become simpler to control and that their insulin requirement had increased.

Pancreatic insufficiency was associated with pain of two types in some of these patients. One type of pain was a colicky right sided pain similar to that seen in the irritable bowel syndrome. The other type of pain was similar to that of chronic pancreatitis before total pancreatectomy but of lesser severity. In some patients, both types of pain responded to correction of pancreatic insufficiency but often took two to four weeks to do so.

\section{WORK}

Of the 27 patients seen regularly in the clinic eight are in full time employment, two of whom are police officers on shift work. Two are well and seeking work. Two are in full time education. Three are housewives not seeking work but are well. Ten are

Table 8 Pancreatic enzyme replacement therapy. Eighteen patients stable (up to 2 bowel actions per day)

\begin{tabular}{|c|c|c|c|}
\hline \multirow[b]{2}{*}{ Enzyme preparation } & \multirow[b]{2}{*}{$n$} & \multicolumn{2}{|c|}{$\begin{array}{l}\text { Daily dose } \\
\text { (number of tablets or capsules) }\end{array}$} \\
\hline & & Median & (Range) \\
\hline $\begin{array}{l}\text { Pancrex V Forte } \\
\text { (Paines and Byrne) }\end{array}$ & 4 & $62 \cdot 5$ & $(30-150)$ \\
\hline $\begin{array}{l}\text { Creon } \\
\text { (Duphar) }\end{array}$ & 11 & 50 & $(15-80)$ \\
\hline $\begin{array}{l}\text { Pancrease } \\
\text { (Johnson and Johnson) }\end{array}$ & 3 & 60 & $(25-80)$ \\
\hline
\end{tabular}

Six patients not stabilised; two patients inadequate records. not working and not likely ever to do so again. Two of the patients operated on this year are not fit, one has recently had endoscopic insertion of stents for a biliary stricture and the other has persistent pain after a leak from the duodenum.

\section{Discussion}

In this series we have described 29 patients who have had total pancreatectomy for intractable pancreatic pain. We do not suggest that this procedure should be undertaken lightly nor do we recommend that it be undertaken in a unit which is not prepared to follow up these patients closely and readmit them when necessary.

The absolute indications for this procedure in chronic pancreatitis are undefined, but in a patient who has failed all other types of therapy or surgery and who is on a high dose of regular opiates, there is little else to offer. It has been our experience that there is a group who can be predicted, from the outset, to do badly from any procedure short of total pancreatectomy - those who have idiopathic pancreatitis or pancreatitis caused by pancreas divisum, who have an inordinate amount of pain associated with only minor diffuse fibrotic changes in the pancreas. Possibly in this very small group there will be a place, in the future, for earlier aggressive surgery: this will not be our recommendation until further evidence is available. Our experience with alcoholic pancreatitis is that provided the patient stops drinking after an appropriate partial resection or drainage the outlook is good, but those who have chronic pancreatitis of non-alcoholic origin due to diffuse disease do less well with partial resection. No patient is accepted for total pancreatectomy if he/she continues to take alcohol, whatever the aetiology of the pancreatitis. 
The large proportion of patients whose disease was attributed to pancreas divisum reflects the belief of the authors ${ }^{13}$ that this congenital variant can cause pancreatitis. Although total pancreatectomy does relieve the pain of end stage chronic pancreatitis we have encountered a difficult problem of recurrent pain in 10 , identical in nature to that which the patient was suffering before the operation. This is never as severe, as frequent or as long lasting as the preoperative pain but is often accompanied by vomiting. Investigation invariably reveals normal liver function tests, endoscopy and a normal ultrasound of the pancreatic bed. These patients may need admission for supervision in weaning off analgesics. We can only speculate as to what the cause of the pain may be as there has never been a proven cause. One cause may be of incorrect diagnosis leading to an inappropriate operation, however, we do not believe this to be the case. Another cause may be a 'phantom' pain similar to that seen after limb amputation. Whatever the cause, the bouts of pain recede with time, and our experience is that patients are pain free within three years of the operation.

The histological examination of the pancreatic tissue removed did not confirm the clinical diagnosis in five cases, indeed in one case the histology was normal despite indicative preoperative investigations; this patient is currently doing well without any analgesia although it is only eight months after her resection and therefore a placebo effect cannot be excluded. The three cases who had only mild pancreatitis are difficult to assess, one has recurrent pain and pethidine addiction, one is a heroin addict managing very well on reducing doses of methadone (remaining pain free) and one is the patient who has hypoglycaemia artefacta but is pain free.

The most common indication for readmission was pain with or without vomiting and diarrhoea; this has been discussed above. In three patients admission was required for stabilisation of diabetes early after pancreatectomy; in all three this was related to poorly controlled pancreatic insufficiency. It is apparent from Table 5 that a number of patients do require readmission for a variety of reasons (although 10 have had no readmissions), the longterm management of these patients commits the clinician to the likelihood of such admissions.

Previous reports have condemned total pancreatectomy as a dangerous procedure, not only from operative mortality, but also from late risks of fatal hypoglycaemia." It is interesting to see that in our group of 24 patients who are still seen regularly, even though eight are exalcoholics and one of these is a drug addict, the management of the diabetes is not a problem. One may hypothesise that on psychological grounds these people are better equipped to face up to diabetes as they made an elective decision to exchange their pain for diabetes whereas a normal diabetic has no such choice.

Our follow up experience of these patients, and indeed those with partial pancreatectomies, suggests that the problems that arise with diabetic control stem from pancreatic exocrine insufficiency rather than any intrinsic instability in the diabetes or the psychology of the patient.

Comparison of the two pancreatectomy groups with the diabetic controls shows that the standard total pancreatectomy group differs from the controls in that they are lighter, require less insulin per kilogram body weight and that their mean glycaemic control is worse. It is worthy of note that the duodenum preserving total pancreatectomy group do not differ significantly from the controls for any of these measurements.

We have been increasing the dosage of enzyme replacement in these patients to try to avoid any diarrhoea: this is not always possible with the strength of lipase available in the current preparations despite enteric coating to avoid deactivation by gastric acid. From Table 8 it may be seen that one of our patients takes 150 tablets per day. Since we started on this policy many patients have commented that not only has their diarrhoea improved, but also their diabetes has been easier to control and has needed a higher dose of insulin. The mechanism we propose is simple: with the rapid intestinal transit secondary to pancreatic insufficiency the absorption of glucose is very unpredictable; the uptake will vary from meal to meal depending on the fat content. There is another factor that can complicate absorption, the presence of the dumping syndrome after a standard pancreatectomy with the standard partial gastrectomy. Previous studies suggest this problem is uncommon $(10-13 \%)$ and rarely alters management. ${ }^{14}$

Our current practice is to try to use only three pancreatic enzyme replacement products, a standard enteric coated tablet preparation (Pancrex V Forte, Paines and Byrne), an enteric coated granular preparation (Creon, Duphar Laboratories) and an enteric coated microspheric preparation (Pancrease, Johnson and Johnson). We usually start our patients on the standard preparation (as it is cheaper) and increase the dose until diarrhoea is controlled. If we cannot control their diarrhoea with 'reasonable' doses we substitute the enteric coated preparation at the same dose; if the diarrhoea is controlled we then reduce the dose in steps every three to four days or if the patient still has diarrhoea increase the dose until this is controlled. A 'reasonable' dose is determined by the patient as they have to take all the tablets or capsules before each meal or snack. We have also 
changed some of our old patients to the enteric coated preparation if they were taking a very high dose or still had diarrhoea.

Psychological factors have an important role in patients with end stage pancreatitis as these patients all have suffered years of chronic pain; additionally many of the patients have problems of dependency to analgesics and/or alcohol. The role of psychological factors in the postoperative diabetic management in this group has not yet been investigated; however, in three patients there has been an obvious problem directly affecting diabetic management in one (hypoglycaemia artefacta) and in two, problems with eating ('anorexia') causing indirect difficulties of diabetic management. We have not had the opportunity to submit our patients to formal preoperative psychological assessment but this would be desirable. In three patients (at least) the poor result of total pancreatectomy possibly could have been predicted preoperatively if there had been an appropriate method of assessment.

This survey of an experience with total pancreatectomy has tried to present the outcome after the operation. To limit observer bias, those who advised operation (PBC, RCGR) were not involved with the data collection (ML, IPL) or the diabetic management (ABK, DCB). The success of the procedure is limited by the inevitable deficiencies which that operation creates, and the outcome appears largely related to the ability of the individual to control the previous drug dependency, the diabetes and the enzyme deficiency. Personality thus becomes a major factor in outcome, and in many patients great support and help is required during the early years following total resection. Our first patient took five years to stabilise since when she has been living normally. Our conclusion in what is a young group of patients is that prolonged care is necessary, and the end result can only be assessed at the five year period.

This work forms part of a thesis submitted to the University of London for the degree of MS.

We are grateful to Dr W Lees and the W H Collins $x$-ray diagnosis department and to the Courtauld Institute for their help in the investigation of the patients. We are grateful to Dr J Rode and the Bland
Sutton Institute of Pathology for their painstaking histological studies. We would like to thank $\mathrm{Mr} \mathrm{S}$ Nightingale and the department of Medical photography for the illustration and Dr P Whitfield for his statistical advice.

\section{References}

1 Sato T, Miyashita E, Matsuno S, Yamauchi $\mathrm{H}$. The role of surgical treatment for chronic pancreatitis. Ann Surg 1986; 203: 266-71.

2 Waugh JM, Dixon CF, Clagett OT, Bollman JL, Sprague RG, Comfort MW. Total pancreatectomy: a symposium presenting four successful cases and a report on metabolic observations. Mayo Clin Proc 1946; 21: 25-46.

3 Whipple AO. Radical surgery for certain cases of pancreatic fibrosis associated with calcareous deposits. Ann Surg 1946; 124: 991-1006.

4 Traverso LW, Longmire WP. Preservation of the pylorus in pancreaticoduodenectomy. Surg Gynecol Obstet 1978; 146: 959-62.

5 Traverso LW, Longmire WP. Preservation of the pylorus in pancreaticoduodenectomy - a follow up evaluation. Ann Surg 1980; 192: 306-10.

6 Newman KD, Braasch JW, Rossi RL, O'CampoGonzales S. Pyloric and gastric preservation with pancreatoduodenectomy. Am J Surg 1983; 145: 152-6.

7 Braasch JW, Gongliang J, Rossi RL. Pancreatoduodenectomy with preservation of the pylorus. World J Surg 1984; 8: 900-5.

8 Russell RCG. Alternative surgical procedures for the management of pancreatic disease [Abstract]. Gut 1985; 26: A652.

9 Lambert MA, Linehan IP, Russell RCG. Duodenumpreserving total pancreatectomy for end-stage chronic pancreatitis. Br J Surg 1987; 74: 35-9.

10 Beger HG, Krautzberger W, Bittner R, Buchler M, Limmer J. Duodenum-preserving resection of the head of the pancreas in patients with severe chronic pancreatitis. Surgery 1985; 97: 467-73.

11 Gall FP, Muhe E, Gebhardt C. Results of partial and total pancreaticoduodenectomy in 117 patients with chronic pancreatitis. World J Surg 1981; 5: 269-75.

12 Documenta Geigy. Scientific tables. 7th ed. Basle: JR Geigy SA, 1970: 172 .

13 Cotton PB. Congenital anomaly of pancreas divisum as cause of obstructive pain and pancreatitis. Gut 1980;21: 105-14.

14 Linehan IP. The dumping syndrome after pancreatoduodenectomy. University of London: MS Thesis 1986. 